\title{
Approximating the phase response curves of square wave bursting
} neurons

\author{
Ikemefuna Agbanusi*1, Alborz Yarahmadi ${ }^{1}$, Amitabha Bose ${ }^{1}$, \\ Jorge Golowasch ${ }^{1,2}$ and Farzan Nadim ${ }^{1,2}$
}

Address: ${ }^{1}$ Dept. of Mathematical Sciences, NJIT, Newark, NJ, USA and 2Dept. of Bio. Sci., Rutgers University, Newark, NJ 07102, USA

Email: Ikemefuna Agbanusi* - ia29@njit.edu; Alborz Yarahmadi - ay24@njit.edu

* Corresponding author

from Seventeenth Annual Computational Neuroscience Meeting: CNS*2008 Portland, OR, USA. 19-24 July 2008

Published: II July 2008

BMC Neuroscience 2008, 9(SuppI I):P24 doi:I0.I I86/I47I-2202-9-SI-P24

This abstract is available from: http://www.biomedcentral.com/I47I-2202/9/SI/P24

(C) 2008 Agbanusi et al; licensee BioMed Central Ltd.

\section{Background}

The phase response curve (PRC) measures the response of an oscillator to the timing of stimulus and here we construct and study the PRC of the bursting PD neuron of the STG in the crab, Cancer borealis. For bursting neurons whose oscillation is composed of an active phase of fast spiking activity and a silent phase, the response is determined by the change in timing of the start of the active phase after the stimulus. PRCs prove useful, when trying to predict the output of neural networks. We compare experimental results with numerical simulations of a Morris-Lecar type bursting model. We see, for instance, that in both cases, the PRCs saturate with large amplitude perturbations. Our new method is to reconstruct the PRC of the active phase by measuring the changes in the timings of the spikes in the active phase when the stimulus occurs while ignoring the effect of the stimulus in the silent phase. This approach should prove insightful in describ-
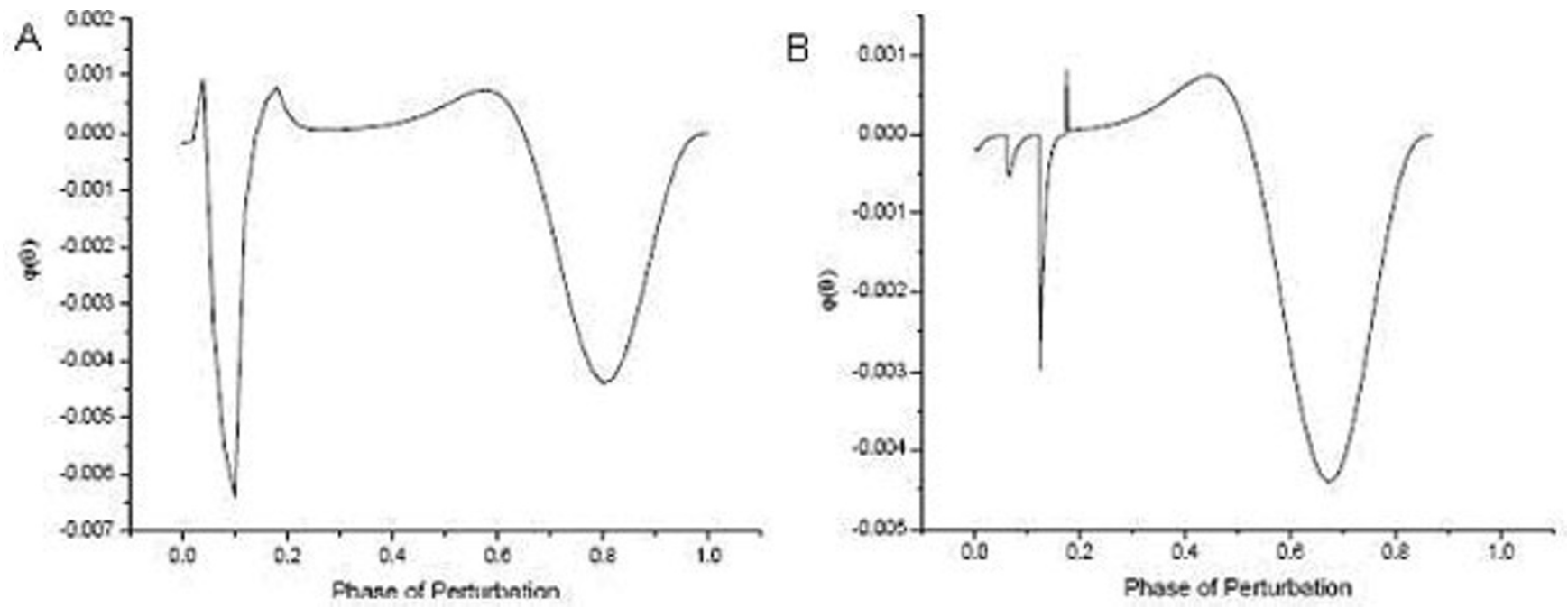

Figure I

Model PRCs. A. Model burst PRC. B. Model PRC constructed from inter-spike PRCs. 
ing more intricate synchronization patterns in coupled bursting cells. We also use ideas from geometric singular perturbation theory to shed some light on the saturation phenomenon.

\section{Results}

The PRC and its approximant for the model neuron are shown in Figure 1. We also show that much of the phase response is due to spike addition (more spikes in active phase), spike deletion (fewer spikes) and burst truncation which is the termination of the active phase. For example, strong inhibition and excitation cause burst truncation and spike addition, respectively, in the active phase. Burst truncation is thus seen to be the key mechanism behind the saturation of the PRCs with amplitude.

\section{Conclusion}

To a first order approximation, we have shown that one can predict the PRC by assuming linear spike shifting in the active phase. We also show the importance of phenomena such as spike addition, deletion and burst truncation in determining the phase response properties of the oscillator.

\section{Acknowledgements}

This research was supported by a UBM grant.
Publish with Biomed Central and every scientist can read your work free of charge

"BioMed Central will be the most significant development for disseminating the results of biomedical research in our lifetime. " Sir Paul Nurse, Cancer Research UK

Your research papers will be:

- available free of charge to the entire biomedical community

- peer reviewed and published immediately upon acceptance

- cited in PubMed and archived on PubMed Central

- yours - you keep the copyright

Submit your manuscript here:

http://www.biomedcentral.com/info/publishing_adv.asp 